\title{
Gene Expression Analysis of Zeaxanthin Epoxidase from the Marine Microalga Dunaliella tertiolecta in Response to Light/Dark Cycle and Salinity
}

\author{
Minjae Kim ${ }^{1}$, Yongsoo Kang ${ }^{2}$, and EonSeon Jin ${ }^{1,3 *}$ \\ ${ }^{1}$ Department of Life Science, College of Natural Sciences, Hanyang University, Seoul 04763, Republic of Korea \\ ${ }^{2}$ Eugene Biotech Co. Ltd., Daejeon 34051, Republic of Korea \\ ${ }^{3}$ Research Institute of Natural Sciences, Hanyang University, Seoul 04763, Republic of Korea
}

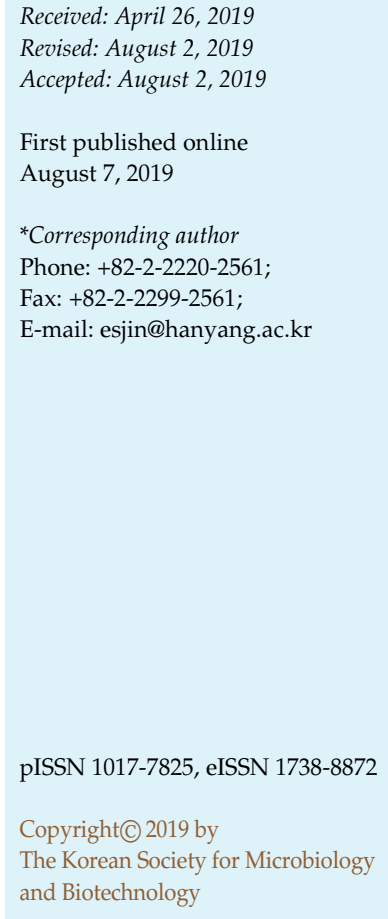

Zeaxanthin is an important pigment in the photo-protection mechanism of microalgae. However, zeaxanthin epoxidase, an enzyme involved in the accumulation and conversion of zeaxanthin, has not been extensively studied in microalgae. In this work, we report the expression pattern of zeaxanthin epoxidase in Dunaliella tertiolecta (DtZEP) at different light and diverse salinity conditions. To confirm the responsiveness to light conditions, the ZEP expression pattern was investigated in photoperiodic (16 h of light and $8 \mathrm{~h}$ of dark) and continuous ( $24 \mathrm{~h}$ of light and $0 \mathrm{~h}$ of dark) light conditions. mRNA expression levels in photoperiodic conditions fluctuated along with the light/dark cycle, whereas those in continuous light remained unchanged. In varying salinity conditions, the highest mRNA and protein levels were detected in cells cultured in $1.5 \mathrm{M} \mathrm{NaCl}$, and ZEP expression levels in cells shifted from $0.6 \mathrm{M} \mathrm{NaCl}$ to $1.5 \mathrm{M} \mathrm{NaCl}$ increased gradually. These results show that mRNA expression of DtZEP responds rapidly to the light/dark cycle or increased salinity, whereas changes in protein synthesis do not occur within a short period. Taken together, we show that DtZEP gene expression responds rapidly to light irradiation and hyperosmotic stress. In addition, ZEP expression patterns in light or salinity conditions are similar to those of higher plants, even though the habitat of $D$. tertiolecta is different.

Keywords: Zeaxanthin epoxidase, Dunaliella tertiolecta, carotenoid biosynthetic pathway, photoperiodic condition, continuous light condition, salinity condition

\section{Introduction}

Zeaxanthin is an important pigment in the photoprotection mechanism of microalgae and higher plants [1, 2]. In these organisms, zeaxanthin is accumulated under excessive light $[2,3]$ or dehydration stress conditions [4-6]. To understand how zeaxanthin is accumulated in response to these environmental conditions, the xanthophyll enzymes have been extensively studied in higher plants [7-9].

After the first report of zeaxanthin epoxidase (ZEP) from Nicotiana plumbaginifolia [9], a variety of ZEPs have been isolated and investigated in higher plants [5, 7, 10-15]. Generally, ZEP is located on the stromal side of the chloroplast thylakoid membrane, and is involved in the conversion of the xanthophyll pigments together with violaxanthin de-epoxidase (VDE), which is located on the luminal side $[8,16]$. When light energy is lower than that required for the saturation of the photosynthetic apparatus, zeaxanthin is converted to violaxanthin by ZEP [2]. On the other hand, when light energy is above the saturation levels of photosynthesis, a reversible reaction is initiated by VDE in the chloroplast, resulting in the accumulation of zeaxanthin [17]. ZEP expression increases in leaves under light conditions, but decreases significantly at drought stress conditions $[5,7,18,19]$. Interestingly, ZEP shows different expression patterns in roots and leaves [5]. ZEP 
expression levels in roots are increased significantly under drought $[5,19]$ or salt stress conditions [20]. These tissuespecific expression patterns of ZEP are thought to be related to different roles of ZEP in various tissues [5].

In microalgae, most studies have focused on identifying the role of the xanthophyll cycle in photo-protection using ZEP mutants [21-23], not on ZEP itself. However, some microalgal ZEPs have been described recently, and their characteristics have begun to be investigated [24, 25]. Although ZEP expression has been extensively studied in higher plants, microalgae and higher plants are morphologically different and are found in completely different environments. Microalgal ZEPs may thus show different expression patterns in response to environmental conditions than those in higher plants, and investigation is warranted.

Zeaxanthin accumulation in response to excessive light and salinity has been reported in Dunaliella tertiolecta [6] and other Dunaliella species [4, 27, 28]. We have previously characterized the DNA sequence and encoded protein of ZEP from D. tertiolecta of the phylum Chlorophyta [24]. In this study, we evaluated the expression pattern of ZEP in response to the light/dark cycle and salinity conditions. We also investigated the expression of carotenoid biosynthetic genes to understand the mechanism of zeaxanthin accumulation under salinity conditions. The characteristics of D. tertiolecta ZEP response to light/dark cycles and salinity conditions were compared to those of higher plant ZEPs.

\section{Materials and Methods}

\section{Strains and Culture Medium}

Dunaliella tertiolecta CCAP 19/42 was used for this study. The composition of specific culture media for Dunaliella species (D media) was described in the previous paper [6]. To produce diverse salinity conditions, the concentration of $\mathrm{NaCl}$ was differently applied to the culture medium according to the purpose of each experiment $(0.3 \mathrm{M}, 0.6 \mathrm{M}$, and $1.5 \mathrm{M})$.

\section{Experimental Light/Dark Cycle and Salinity Conditions}

For the light/dark cycle experiments, cells were grown on $0.6 \mathrm{M}$ $\mathrm{NaCl} \mathrm{D}$ media under two different conditions; a photoperiodic condition ( $16 \mathrm{~h}$ of light and $8 \mathrm{~h}$ of dark) and a continuous light condition ( $24 \mathrm{~h}$ of light and $0 \mathrm{~h}$ of dark). The irradiance and temperature were maintained to $150 \pm 10 \mu \mathrm{mol}$ photons $\mathrm{m}^{-2} \mathrm{~s}^{-1}$ and $25^{\circ} \mathrm{C}$.

For the salinity condition experiments, cells were grown respectively on $0.3 \mathrm{M}, 0.6 \mathrm{M}$, and $1.5 \mathrm{M} \mathrm{NaCl} \mathrm{D}$ media. Light and temperature conditions were maintained at $150 \pm 10 \mu \mathrm{mol}$ photons $\mathrm{m}^{-2} \mathrm{~s}^{-1}$ of continuous light and $25^{\circ} \mathrm{C}$. The cells were sub- cultured more than twice to let them adapt to each salinity level. Also, the cells grown on $0.6 \mathrm{M} \mathrm{NaCl} \mathrm{D} \mathrm{media} \mathrm{were} \mathrm{transfer} \mathrm{into}$ $1.5 \mathrm{M} \mathrm{NaCl} \mathrm{D}$ media to investigate the response to increased salinity condition.

\section{Quantitative Real-Time PCR Analysis}

Total RNA was extracted from the cells using RNeasy Plant Mini Kit (Qiagen, Germany), and cDNA was synthesized using 2× Reverse Transcription Master Premix (ELPiS Biotech, Republic of Korea). To perform the quantitative real-time PCR (qRT-PCR), synthesized cDNA was mixed with SYBR Premix (Takara, Japan) and amplified by the Thermal Cycler Dice Real-Time System TP 8200 (Takara). The gene of $60 \mathrm{~S}$ ribosomal protein large subunit (60S) was used for reference. Results were analyzed by the Ct method. Sequences of primers for qRT-PCR were as follows; ZEP_Fwd (5'-ACAAGCATGGTACGGGGATG-3'), ZEP_Rev (5'CATGGCCTGCATGACCACTA-3'), GGPPS_Fwd (5'-CATTGC CATTCTTGCCGGAG-3'), GGPPS_Rev (5'-CACCTCCTGGTTTTC GCTCT-3'), PSY_Fwd (5'-CAGCTCACCAACATTCTGCG-3'), PSY_Rev (5'-TACCCCATCCTCTGCTTCCT-3'), PDS_Fwd (5'ACGGAGAGATTGTGGAGGGA-3'), PDS_Rev (5'-ACTGTGGAT AGCTTGCGGTC-3'), LCYB_Fwd (5'-GGTGTGACCTTCCTCACC AG-3'), LCYB_Rev (5'-AGCTCAAAGGGATGCGACTC-3'), 60S_Fwd (5'-CCAAGCTCACCTACGAGCAG-3'), 60S_Rev (5'-GTCCACCAA CCCGAATCCAT-3').

\section{Western Blot Analysis}

Lanes were equally loaded with crude extracts on the basis of cell number $\left(100 \times 10^{4}\right.$ cells per lane). Western blot analysis was carried out following the same process as described in the previous paper [24]. Primary antibodies used for western blot analysis; the custom-made polyclonal antibody of ZEP $(1: 5,000)$ used in our previous paper [24] and the commercial antibody of ATP synthase $\beta$-subunit (ATP- $\beta$; Agrisera AS05 085, 1:10,000) as control protein. Secondary HRP-conjugated goat anti-rabbit IgG $(\mathrm{H}+\mathrm{L})$ antibody (Invitrogen, USA, 1:20,000) was used too.

\section{Carotenoid Analysis}

Samples of $0.5 \mathrm{ml}$ each were harvested by centrifugation $(14,000 \times g, 2 \mathrm{~min})$, and the number of cells in the samples was counted for calculation of pigment content as the same cell density $\left(10^{6}\right.$ cells). Pigment analysis was performed with highperformance liquid chromatography (HPLC) following the method as described in the previous paper [6].

\section{Results}

\section{Pigment Composition and DtZEP Expression Are Regulated under Light/Dark Conditions}

To examine the effects of the light/dark cycle on DtZEP expression, cells were cultured in photoperiodic (16 h of light and $8 \mathrm{~h}$ of dark) and continuous light (24 h of light 

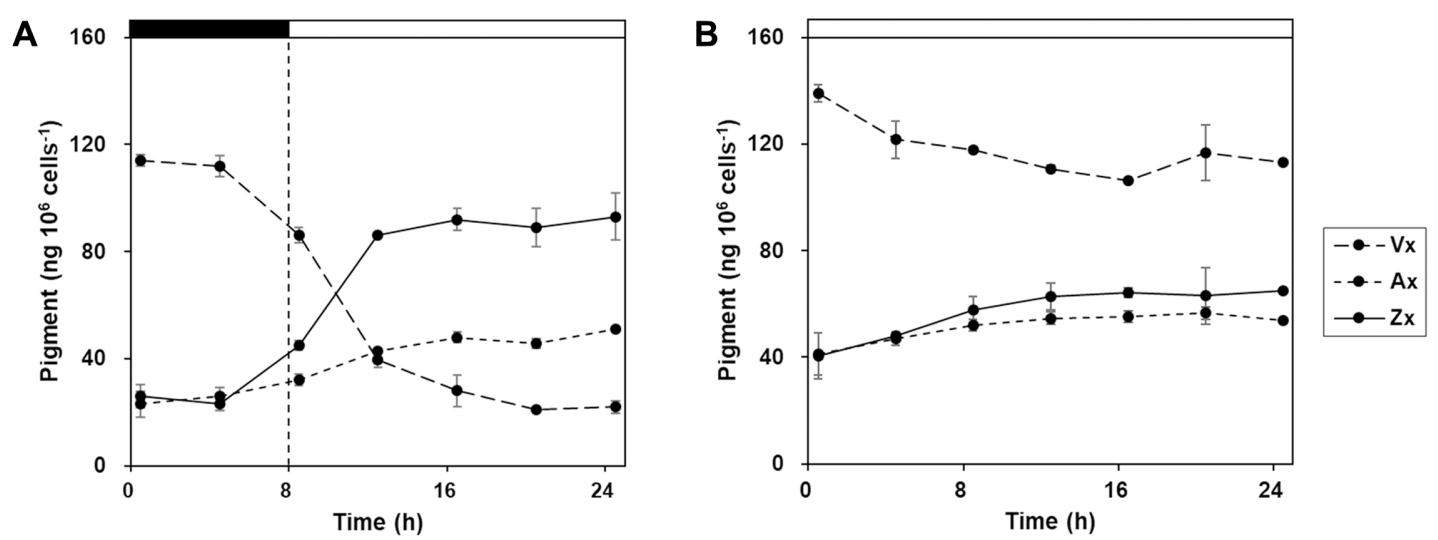

Fig. 1. Changes in xanthophyll pigment content in Dunaliella tertiolecta under different light conditions.

(A) Cells cultured under photoperiodic conditions (16 h of light and $8 \mathrm{~h}$ of dark); (B) Cells cultured under continuous light condition (24 h of light and $0 \mathrm{~h}$ of dark). Vx, violaxanthin; Ax, antheraxanthin; $\mathrm{Zx}$, zeaxanthin.

and $0 \mathrm{~h}$ of dark) conditions. Using fully adapted cells, the composition of xanthophyll pigments and the expression levels of $D t Z E P$ were analyzed every $4 \mathrm{~h}$. In cells cultured under photoperiodic conditions, zeaxanthin and violaxanthin levels increased and decreased, respectively, when cells were exposed to light (Fig. 1A). In contrast, zeaxanthin and violaxanthin levels in cells cultured under continuous light remained almost unchanged (Fig. 1B).

DtZEP mRNA levels in cells cultured under photoperiodic conditions showed light-responsiveness and increased after light exposure (Fig. 2A). In contrast, no significant change in mRNA levels was observed in cells adapted to continuous light (Fig. 2B). Protein levels were similar in cells cultured under photoperiodic and continuous light conditions (Figs. 2C and 2D). In both conditions, protein expression patterns were different from those of mRNA expression.

\section{Carotenoid Content and DtZEP Expression Are Affected by Salinity}

Cells were cultured under three different salinity conditions for adaptation; $0.3 \mathrm{M}, 0.6 \mathrm{M}$, and $1.5 \mathrm{M} \mathrm{NaCl} \mathrm{D}$
A

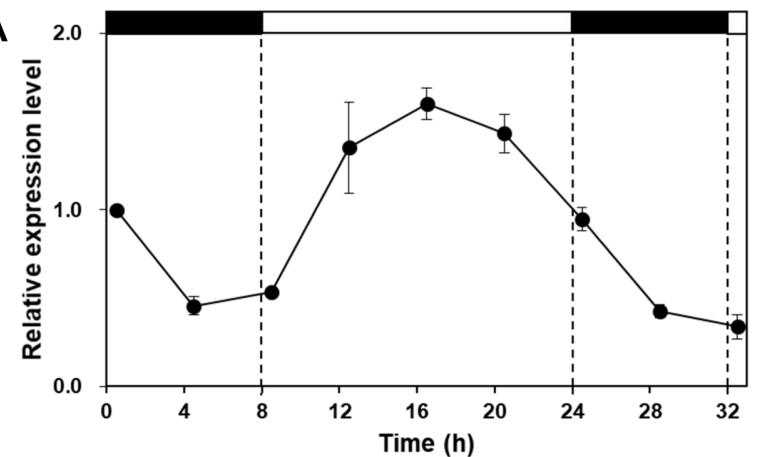

C

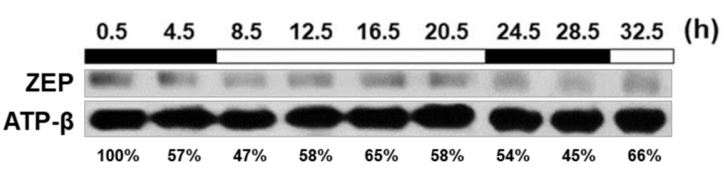

B

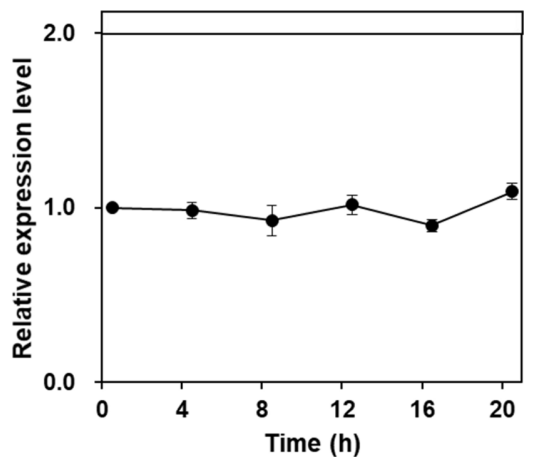

D

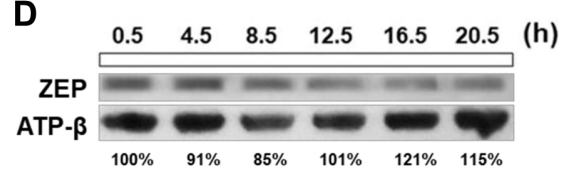

Fig. 2. Changes in DtZEP expression under different light conditions.

(A) mRNA expression pattern in cells under photoperiodic conditions; (B) mRNA expression pattern in cells under continuous light conditions; (C) Protein expression pattern in cells under photoperiodic conditions; (D) Protein expression pattern in cells under continuous light conditions. mRNA levels are expressed relative to the value corresponding to $0.5 \mathrm{~h}$. Error bars indicate the standard errors of triplicated samples. ATP- $\beta$ protein was used as a loading control. 
A

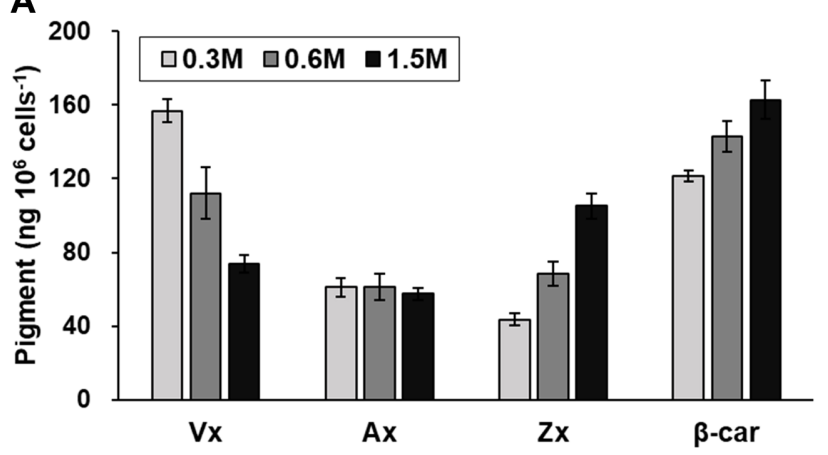

B

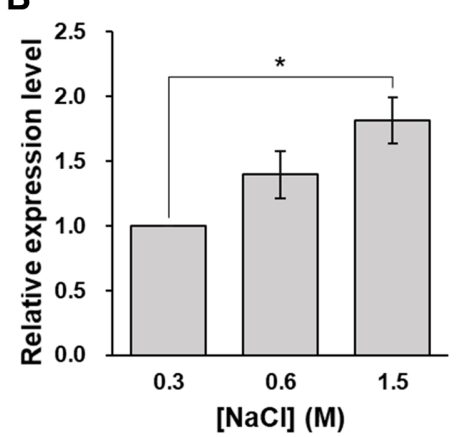

C

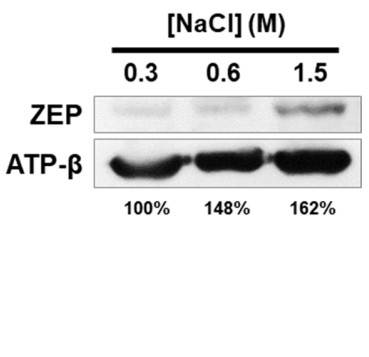

Fig. 3. Effects of salinity on carotenoid content and DtZEP expression.

(A) $\beta$-Branch carotenoid content ( $\mathrm{Vx}$, violaxanthin; $\mathrm{Ax}$, antheraxanthin; $Z x$, zeaxanthin; $\beta$-car, $\beta$-carotene); (B) mRNA expression levels calculated relative to the value corresponding to $0.3 \mathrm{M}$; (C) Protein expression levels of DtZEP. Error bars indicate the standard errors of triplicated samples. Statistical analysis was performed using Student's $t$-test; * $p<0.05$. ATP- $\beta$ protein was used as a loading control. media. Pigment content and expression levels of DtZEP were analyzed in cells at the stationary stage (10 days from initial inoculation). Pigment analysis was conducted of $\beta$ branch carotenoids; $\beta$-carotene, zeaxanthin, antheraxanthin, and violaxanthin (Fig. 3A). Cells cultured in $1.5 \mathrm{M} \mathrm{NaCl} D$ media contained high content of $\beta$-carotene and zeaxanthin. The amount of zeaxanthin in $1.5 \mathrm{M} \mathrm{NaCl}$ was approximately 2-fold higher than that in $0.3 \mathrm{M} \mathrm{NaCl}$. No difference in antheraxanthin was observed in various salinity conditions, whereas violaxanthin content decreased in response to an increase in salinity.

$D t Z E P$ expression in different salinity conditions was analyzed at the mRNA and protein levels. The highest gene expression levels were observed in cells cultured at $1.5 \mathrm{M}$ $\mathrm{NaCl} \mathrm{D}$ media, which was more than $70 \%$ higher than those of in cells cultured at $0.3 \mathrm{M} \mathrm{NaCl}$ (Fig. 3B). Similar patterns were observed in protein expression levels. Western blotting results show that there was significant accumulation of DtZEP protein in cells cultured at a higher salinity than $0.3 \mathrm{M} \mathrm{NaCl}$ D media (Fig. 3C).

\section{Hyperosmotic Stress Affects Carotenoid Content and DtZEP Expression}

After cells cultured at $0.6 \mathrm{M} \mathrm{NaCl}$ were transferred to $1.5 \mathrm{M} \mathrm{NaCl}$, the kinetics of pigment content and DtZEP expression levels were determined. Zeaxanthin was significantly accumulated after the $6 \mathrm{~h}$ time point, whereas violaxanthin content decreased steadily during the experiments. In addition, the content of antheraxanthin
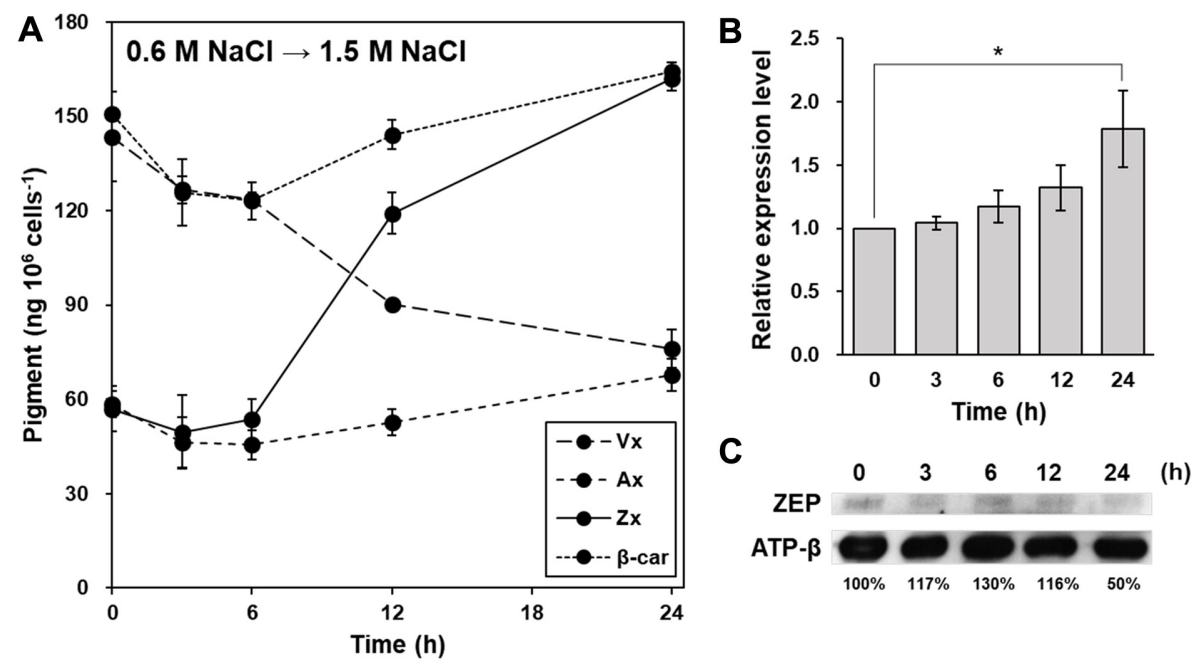

Fig. 4. Effects of hyperosmotic stress on $\beta$-branch carotenoid content and DtZEP expression.

(A) Changing pattern in $\beta$-branch carotenoid content (Vx, violaxanthin; Ax, antheraxanthin; Zx, zeaxanthin; $\beta$-car, $\beta$-carotene); (B) mRNA expression levels calculated relative to the value corresponding to $0 \mathrm{~h}$; (C) Protein expression levels of DtZEP. Error bars indicate the standard errors of triplicated samples. Statistical analysis was performed using Student's $t$-test; ${ }^{*} p<0.05$. ATP- $\beta$ protein was used as a loading control. 
and $\beta$-carotene gradually increased after the $6 \mathrm{~h}$ time point (Fig. 4A).

The kinetics of DtZEP expression were also determined at the mRNA and protein levels. mRNA levels of DtZEP increased gradually until $24 \mathrm{~h}$, and the maximal levels were approximately 1.7-fold higher than the initial levels (Fig. 4B). However, the protein expression patterns were different from those of mRNA expression (Fig. 4C).

Zeaxanthin and $\beta$-Carotene Accumulation in Response to Hyperosmotic Stress Is Related to Upregulation of the Carotenoid Biosynthetic Pathway

In higher plants, the carotenoid content is closely related to the expression level of carotenoid biosynthetic genes [29, 30]. We confirmed the varying carotenoid content in response to changes in salinity (Figs. 3A and 4A), and then investigated the mRNA expression levels of carotenoid biosynthetic genes, especially the genes of the $\beta$-branch synthetic pathway, under different salinity conditions (circled on Fig. 5A). Cells cultured at $0.3 \mathrm{M}, 0.6 \mathrm{M}$, and $1.5 \mathrm{M} \mathrm{NaCl}$ were used for analysis. mRNA expression levels of GGPS, PSY, LCYB and ZEP at $1.5 \mathrm{M} \mathrm{NaCl}$ were approximately 1.5 -fold higher than those at $0.3 \mathrm{M} \mathrm{NaCl}$ (Fig. 5B). In contrast, PDS expression levels at $1.5 \mathrm{M} \mathrm{NaCl}$ were approximately $10 \%$ higher than those at $0.3 \mathrm{M} \mathrm{NaCl}$.

\section{Discussion}

Zeaxanthin epoxidase (ZEP) has been studied in many species of Chlorophyta, but most of them are higher plants [5, 7, 9-13]. Recently, we reported the ZEP sequence of the marine microalga, Dunaliella tertiolecta CCAP 19/42 [24]. This microalgal species is classified as a Chlorophyta and is able to grow at diverse salinity conditions [26], unlike higher plants. Gene expression in living organisms can be different according to their environments. Therefore, we studied marine microalgal ZEP and compared it to higher plant $Z E P$ s. This is the first report of an investigation of $Z E P$ expression in marine microalgae at the environmental conditions affecting the expression of higher plant ZEPs.

Light and dehydrating conditions are representative triggering factors of ZEP expression in higher plants [5, 15, 19]. Characterization of $Z E P$ expression in response to light conditions has been extensively examined in leaves of higher plants. The mRNA expression of ZEP in leaves shows an oscillating pattern following the diurnal rhythm $[7,18,19]$, and is similar to the variation pattern of xanthophyll pigments [18]. In this study, the zeaxanthin and violaxanthin content in D. tertiolecta increased and decreased, respectively, immediately after light exposure (Fig. 1A), similar to plant leaves. In addition, the DtZEP
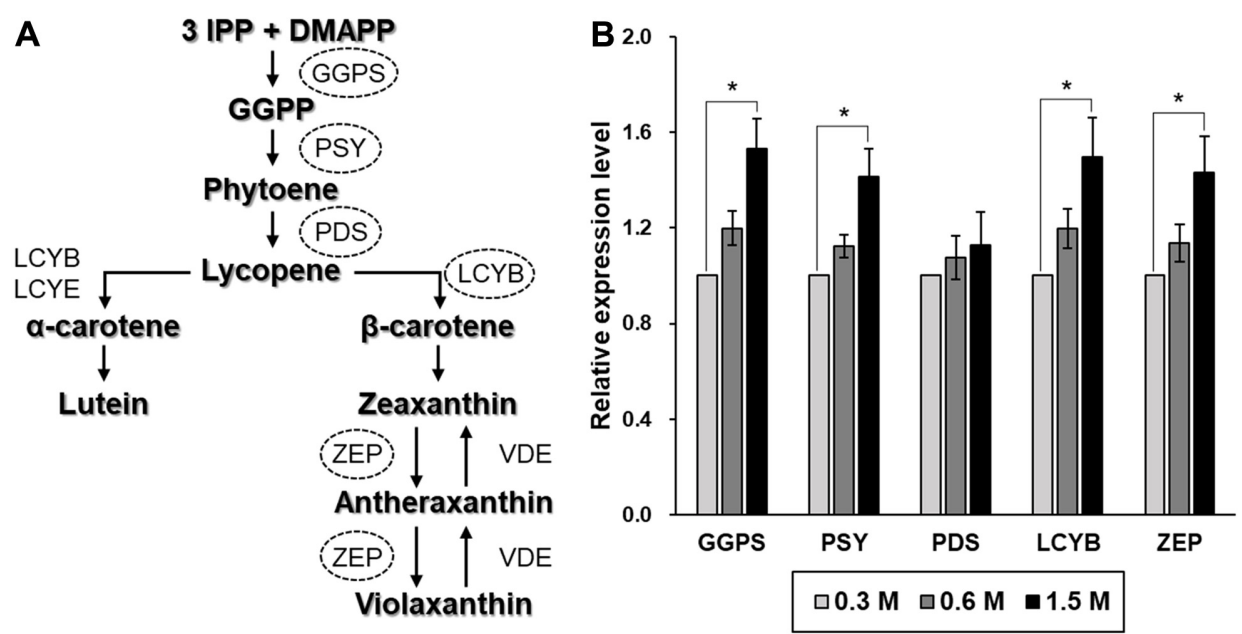

Fig. 5. Gene expression levels of the $\beta$-branch carotenoid synthetic pathway in Dunaliella tertiolecta under different salinity conditions.

(A) Schematic outline of the carotenoid biosynthetic pathway; (B) mRNA expression levels calculated relative to the value corresponding to $0.3 \mathrm{M}$ $\mathrm{NaCl}$. IPP, isopentenyl pyrophosphate; DMAPP, dimethylallyl diphosphate; GGPP, geranylgeranyl pyrophosphate; GGPS, geranylgeranyl pyrophosphate synthase; PSY, phytoene synthase; PDS, phytoene desaturase; LCYB, lycopene $\beta$-cyclase; LCYE, lycopene $\varepsilon$-cyclase; ZEP, zeaxanthin epoxidase; VDE, violaxanthin de-epoxidase. Error bars indicate the standard errors of three independent measurements. Statistical analysis was performed using Student's $t$-test; ${ }^{*} p<0.05$. 
expression showed a pronounced difference between photoperiodic ( $16 \mathrm{~h}$ of light and $8 \mathrm{~h}$ of dark) and continuous light conditions (Fig. 2). Cells adapted to a light/dark cycle showed an oscillating pattern, whereas cells cultured under continuous light showed a mostly unchanging pattern. The expression of the DtZEP protein varies with light/dark cycle, but unlike the level of DtZEP mRNA, the degree of the protein level change is moderate. These results indicate that transcription of DtZEP is rapidly regulated by light, but the translation of DtZEP may not be responsive to light.

In dehydrating conditions, ZEP expression in roots is strongly induced. Unlike $Z E P$ in leaves, the expression of $Z E P$ in roots is enhanced significantly by drought stress [5, 19] or salt stress [20] conditions. In this study, we examined the expression levels of DtZEP at diverse salinity conditions (0.3 M, 0.6 M, and 1.5 M NaCl). Pigment analysis confirmed that the cells contained higher amounts of zeaxanthin and $\beta$-carotene in higher salinity conditions (Fig. 3A). In addition, high expression levels of DtZEP were detected in cells cultured at $1.5 \mathrm{M} \mathrm{NaCl}$ (Fig. 3B). To investigate the effect of hyperosmotic stress, we analyzed the kinetics of changes in pigment content and mRNA expression of DtZEP. When cells at $0.6 \mathrm{M} \mathrm{NaCl}$ were transferred to $1.5 \mathrm{M}$ $\mathrm{NaCl}$, zeaxanthin and $\beta$-carotene began to accumulate after $6 \mathrm{~h}$ (Fig. 4A). Gene expression levels also increased gradually for $24 \mathrm{~h}$ until reaching 1.7-fold the initial levels (Fig. 4B). However, protein expression of DtZEP did not follow mRNA expression, similarly to the results at light/ dark cycle conditions (Fig. 2) and those from studies in higher plants [5]. These results suggest that enzyme reaction and transcription of DtZEP rapidly respond to hyperosmotic stress, but the changes in transcription levels are not reflected in the protein levels in a short time.

Zeaxanthin and $\beta$-carotene accumulation in response to salinity conditions have been reported in other Dunaliella species [4, 6, 27, 28]. Borowizka et al. (1990) reported that the proportion of zeaxanthin as a percentage of total carotenoids increases following a salinity up-shock [27]. Kim et al. (2017) also reported that cells cultured at $3.0 \mathrm{M}$ $\mathrm{NaCl}$ have 2-fold higher zeaxanthin content than at $0.3 \mathrm{M}$ $\mathrm{NaCl}$ [6]. As expected, the mRNA levels of carotenoid biosynthetic genes were the highest in cells at $1.5 \mathrm{M} \mathrm{NaCl}$ (Fig. 5). Especially, the expression levels of phytoene synthase, a rate-limiting step of carotenoid biosynthesis [30], was 1.5-fold higher in cells at $1.5 \mathrm{M} \mathrm{NaCl}$ than at $0.3 \mathrm{M}$ $\mathrm{NaCl}$. Our results show that zeaxanthin and $\beta$-carotene accumulation in Dunaliella species seems to be associated with up-regulation of carotenoid biosynthesis when cells are exposed to increased salinity.

In summary, DtZEP gene expression was modulated in response to light similarly to ZEPs in leaves of higher plants. DtZEP expression also markedly increased in response to increased salinity, similar to ZEP expression in roots. Consequently, our results show that the expression patterns of ZEP at light or salinity conditions are similar to those of higher plants, even if the habitat of D. tertiolecta is completely different. In addition, our results suggest the possibility of increasing zeaxanthin content in $D$. tertiolecta through modulation of the light/dark cycle and salinity conditions.

\section{Acknowledgments}

This research was supported by the Business for Cooperative R\&D between Industry, Academy, and Research Institute (S2449124) funded by the Korea Government (Ministry of SMEs and Startups) and the Korea CCS R\&D Center (KCRC) (NRF-2014M1A8A1049273).

\section{Conflicts of Interest}

The authors have no financial conflicts of interest to declare.

\section{References}

1. Jahns P, Holzwarth AR. 2012. The role of the xanthophyll cycle and of lutein in photoprotection of photosystem II. Biochim. Biophys. Acta 1817: 182-193.

2. Goss R, Jakob T. 2010. Regulation and function of xanthophyll cycle-dependent photoprotection in algae. Photosynth. Res. 106: 103-122.

3. Demmig-Adams B, Adams WW. 1996. The role of xanthophyll cycle carotenoids in the protection of photosynthesis. Trends Plant Sci. 1: 21-26.

4. Cowan A, Logie M, Rose P, Phillips L. 1995. Stress induction of zeaxanthin formation in the $\beta$-carotene accumulating alga Dunaliella salina Teod. J. Plant Physiol. 146: 554-562.

5. Schwarz N, Armbruster U, Iven T, Brückle L, Melzer M, Feussner I, et al. 2014. Tissue-specific accumulation and regulation of zeaxanthin epoxidase in Arabidopsis reflect the multiple functions of the enzyme in plastids. Plant Cell Physiol. 56: 346-357.

6. Kim M, Ahn J, Jeon H, Jin E. 2017. Development of a Dunaliella tertiolecta strain with increased zeaxanthin content using random mutagenesis. Mar. Drugs 15: pii.E189.

7. Audran C, Borel C, Frey A, Sotta B, Meyer C, Simonneau T, et al. 1998. Expression studies of the zeaxanthin epoxidase gene in Nicotiana plumbaginifolia. Plant Physiol. 118: 1021-1028. 
8. Hieber AD, Bugos RC, Yamamoto HY. 2000. Plant lipocalins: violaxanthin de-epoxidase and zeaxanthin epoxidase. Biochim. Biophys. Acta 1482: 84-91.

9. Marin E, Nussaume L, Quesada A, Gonneau M, Sotta B, Hugueney $\mathrm{P}$, et al. 1996. Molecular identification of zeaxanthin epoxidase of Nicotiana plumbaginifolia, a gene involved in abscisic acid biosynthesis and corresponding to the ABA locus of Arabidopsis thaliana. EMBO J. 15: 2331.

10. Burbidge A, Grieve T, Terry C, Corlett J, Thompson A, Taylor I. 1997. Structure and expression of a cDNA encoding zeaxanthin epoxidase, isolated from a wilt-related tomato (Lycopersicon esculentum Mill.) library. J. Exp. Bot. 48: 1749-1750.

11. Wu C, Zhou B. 2018. Characterization of a sterile dwarf mutant and the cloning of zeaxanthin epoxidase in Asian cotton (Gossypium arboreum L.). Plant Growth Regul. 85: 57-72.

12. Yang Q, Yuan D, Shi L, Capell T, Bai C, Wen N, et al. 2012. Functional characterization of the Gentiana lutea zeaxanthin epoxidase (GlZEP) promoter in transgenic tomato plants. Transgenic Res. 21: 1043-1056.

13. Zhang Z, Wang Y, Chang L, Zhang T, An J, Liu Y, et al. 2016. MsZEP, a novel zeaxanthin epoxidase gene from alfalfa (Medicago sativa), confers drought and salt tolerance in transgenic tobacco. Plant Cell Rep. 35: 439-453.

14. Bugos RC, Hieber AD, Yamamoto HY. 1998. Xanthophyll cycle enzymes are members of the lipocalin family, the first identified from plants. J. Biol. Chem. 273: 15321-15324.

15. Audran C, Liotenberg S, Gonneau M, North H, Frey A, TapWaksman $\mathrm{K}$, et al. 2001. Localisation and expression of zeaxanthin epoxidase mRNA in Arabidopsis in response to drought stress and during seed development. Funct. Plant Biol. 28: 1161-1173.

16. Hager A, Holocher K. 1994. Localization of the xanthophyllcycle enzyme violaxanthin de-epoxidase within the thylakoid lumen and abolition of its mobility by a (light-dependent) pH decrease. Planta 192: 581-589.

17. Bratt CE, Arvidsson P-O, Carlsson M, Åkerlund H-E. 1995. Regulation of violaxanthin de-epoxidase activity by $\mathrm{pH}$ and ascorbate concentration. Photosynth. Res. 45: 169-175.

18. North HM, Frey A, Boutin J-P, Sotta B, Marion-Poll A. 2005. Analysis of xanthophyll cycle gene expression during the adaptation of Arabidopsis to excess light and drought stress: Changes in RNA steady-state levels do not contribute to short-term responses. Plant Sci. 169: 115-124.
19. Thompson AJ, Jackson AC, Parker RA, Morpeth DR, Burbidge A, Taylor IB. 2000. Abscisic acid biosynthesis in tomato: regulation of zeaxanthin epoxidase and 9-cisepoxycarotenoid dioxygenase mRNAs by light/dark cycles, water stress and abscisic acid. Plant Mol. Biol. 42: 833-845.

20. Ruiz-Sola MÁ, Arbona V, Gómez-Cadenas A, RodríguezConcepción M, Rodríguez-Villalón A. 2014. A root specific induction of carotenoid biosynthesis contributes to ABA production upon salt stress in Arabidopsis. PLoS One 9: e90765.

21. Jin E, Yokthongwattana K, Polle JE, Melis A. 2003. Role of the reversible xanthophyll cycle in the photosystem II damage and repair cycle in Dunaliella salina. Plant Physiol. 132: 352-364.

22. Baroli I, Do AD, Yamane T, Niyogi KK. 2003. Zeaxanthin accumulation in the absence of a functional xanthophyll cycle protects Chlamydomonas reinhardtii from photooxidative stress. Plant Cell 15: 992-1008.

23. Niyogi KK, Bjorkman O, Grossman AR. 1997. Chlamydomonas xanthophyll cycle mutants identified by video imaging of chlorophyll fluorescence quenching. Plant Cell 9: 1369-1380.

24. Kim M, Kang J, Kang Y, Kang B, Jin E. 2018. Loss of function in Zeaxanthin Epoxidase of Dunaliella tertiolecta caused by a single amino acid mutation within the substrate-binding site. Mar. Drugs 16: 418.

25. Eilers U, Dietzel L, Breitenbach J, Büchel C, Sandmann G. 2016. Identification of genes coding for functional zeaxanthin epoxidases in the diatom Phaeodactylum tricornutum. J. Plant Physiol. 192: 64-70.

26. Borowitzka MA, Siva CJ. 2007. The taxonomy of the genus Dunaliella (Chlorophyta, Dunaliellales) with emphasis on the marine and halophilic species. J. Appl. Phycol. 19: 567-590.

27. Borowitzka MA, Borowitzka LJ, Kessly D. 1990. Effects of salinity increase on carotenoid accumulation in the green alga Dunaliella salina. J. Appl. Phycol. 2: 111-119.

28. Park S, Kim M, Lee S-G, Lee Y, Choi H-K, Jin E. 2015. Contrasting photoadaptive strategies of two morphologically distinct Dunaliella species under various salinities. J. Appl. Phycol. 27: 1053-1062.

29. Cazzonelli CI, Pogson BJ. 2010. Source to sink: regulation of carotenoid biosynthesis in plants. Trends Plant Sci. 15: 266-274.

30. Lu S, Li L. 2008. Carotenoid metabolism: biosynthesis, regulation, and beyond. J. Integr. Plant Biol. 50: 778-785. 